\title{
Parâmetros bioquímicos sanguíneos, balanço de nitrogênio e metabolizabilidade da energia bruta em suínos alimentados com dietas contendo diferentes balanços eletrolíticos
}

\section{Blood biochemical parameters, nitrogen balance and gross energy metabolizability in pigs fed with different dietary electrolyte balances}

\author{
Maurício Osvaldo Wochner'; Paulo Cesar Pozza ${ }^{2 *}$; Ricardo Vianna Nunes ${ }^{3}$; \\ Magali Soares dos Santos Pozza ${ }^{3}$; André Cristiano Lohman; \\ Luís Daniel Giusti Bruno ${ }^{3}$; Mayara Rodrigues ${ }^{5}$; Tiago Junior Pasquetti ${ }^{6}$
}

\section{Resumo}

\begin{abstract}
Objetivou-se com esse trabalho avaliar diferentes balanços eletrolíticos das dietas (BED) sobre os parâmetros bioquímicos sanguíneos, balanços de nitrogênio e a metabolizabilidade da energia bruta, de suínos na fase inicial. Foram utilizados 16 suínos, machos castrados, com peso inicial de 27,95 $\mathrm{kg}$, distribuídos individualmente em gaiolas metabólicas, em um delineamento experimental em blocos ao acaso com quatro tratamentos (BED de 160, 208, 257 e $305 \mathrm{mEq} / \mathrm{kg}$ ) e quatro repetições. Os parâmetros bioquímicos sanguíneos avaliados foram cloretos, potássio, sódio e uréia no soro. $\mathrm{O}$ $\mathrm{pH}$ da urina também foi avaliado, e as variáveis utilizadas no balanço de nitrogênio $(\mathrm{N})$ foram o $\mathrm{N}$ ingerido, $\mathrm{N}$ excretado nas fezes, $\mathrm{N}$ excretado na urina, $\mathrm{N}$ absorvido, $\mathrm{N}$ retido, $\mathrm{N}$ retido/ $\mathrm{N}$ absorvido e excreção total de N. Foram determinados os coeficientes de digestibilidade e metabolizabilidade da energia bruta e seus respectivos valores de energia digestível e metabolizável. Os valores de $\mathrm{pH}$ urinário aumentaram $(\mathrm{P}<0,01)$ linearmente em função dos níveis crescentes do BED, variando de 6,90 a 8,03. Os resultados obtidos para cloretos, potássio e as variáveis dos balanços de nitrogênio e da energia bruta foram semelhantes $(\mathrm{P}>0,05)$ entre os $\mathrm{BED}$ avaliados. Houve aumento linear $(\mathrm{P}<0,01)$ na concentração de sódio no soro sanguíneo em função do aumento do BED, com valores de 2,91; 3,03; 3,27 e 3,18 $\mathrm{g} / \mathrm{l}$, respectivamente para os diferentes tratamentos. Os níveis de uréia no soro sanguíneo aumentaram linearmente $(\mathrm{P}<0,01)$, apresentando valores de 26,$21 ; 28,64 ; 34,32$ e $32,89 \mathrm{mg} / \mathrm{dl}$. Concluiu-se que o aumento do balanço eletrolítico da dieta, de 160 a $305 \mathrm{mEq} / \mathrm{kg}$, proporcionou maiores concentrações de uréia e sódio do soro sanguíneo, e maiores valores de $\mathrm{pH}$ na urina de suínos na fase inicial.

Palavras-chave: Eletrólitos, energia metabolizável, parâmetros fisiológicos, sódio
\end{abstract}

\footnotetext{
${ }^{1}$ Zootecnista, Universidade Estadual do Oeste do Paraná, UNIOESTE, Marechal Cândido Rondon, PR. E-mail: manomw@, hotmail.com

${ }^{2}$ Prof. do Dept ${ }^{\circ}$ de Zootecnia. Universidade Estadual de Maringá, UEM, Maringá, PR. Bolsista de Produtividade em Pesquisa da Fundação Araucária. E-mail: pcpozza@yahoo.com.br

${ }^{3}$ Profs. da UNIOESTE, Marechal Cândido Rondon, PR. E-mail: nunesrv@hotmail.com; magaspozza@hotmail.com; ldgbruno@ unioeste.br

${ }^{4}$ Zootecnista, UNIOESTE, Marechal Cândido Rondon, PR. E-mail: andre12acl@hotmail.com

${ }^{5}$ Doutoranda, Faculdade de Medicina Veterinária e Zootecnia, UNESP, Botucatu, SP. E-mail: mayara_rodriguez@yahoo.com.br

${ }^{6}$ Doutorando, Programa de Pós-graduação em Zootecnia, UEM, Maringá, PR. E-mail: pasquettizoo@yahoo.com.br

* Autor para correspondência
} 


\begin{abstract}
The aim of this study was to evaluate different dietary electrolyte balance (DEB) on the blood biochemical parameters, nitrogen balances and crude metabolizable energy of swine in the initial phase. Sixteen barrows were used, averaging $27.95 \mathrm{~kg}$ of initial weight, allotted individually in metabolic cages in a randomized blocks design with four treatments (DEB of 160, 208, 257 and $305 \mathrm{mEq} / \mathrm{kg}$ ) and 4 replicates. The blood biochemical parameters analyzed were chloride, potassium, sodium and urea in blood. Urine $\mathrm{pH}$ was also evaluated, and the parameters evaluated in nitrogen $(\mathrm{N})$ balance were $\mathrm{N}$ intake, fecal $\mathrm{N}, \mathrm{N}$ excreted in urine, absorbed $\mathrm{N}, \mathrm{N}$ retention, retained $\mathrm{N} /$ absorbed $\mathrm{N}$ and total excretion of $\mathrm{N}$. The gross energy digestibility and metabolizibility coefficients were determined, and the respectives values of digestible and metabolizable energy. The values of urinary $\mathrm{pH}$ increased $(\mathrm{P}<0.01)$ linearly with increasing levels of DEB, ranging from 6.90 to 8.03 . The results for chloride, potassium and nitrogen balances of variables and gross energy were similar $(\mathrm{P}>0.05)$ between the evaluated DEB. A linear increase $(\mathrm{P}<0.01)$ was also observed for sodium concentrations in blood serum due to the increase of DEB, with values of 2.91, 3.03, 3.27 and $3.18 \mathrm{~g} / 1$, respectively for the different treatments. Urea levels in blood serum increased linearly $(\mathrm{P}<0.01)$, with values of $26.21,28.64,34.32$ and 32.89 $\mathrm{mg} / \mathrm{dl}$. It was concluded that increasing the dietary electrolyte balance, from 160 to $305 \mathrm{mEq} / \mathrm{kg}$ resulted in higher concentrations of urea and sodium in blood serum, and higher $\mathrm{pH}$ values in the urine of swine in the initial phase.
\end{abstract}

Key words: Electrolytes, metabolizable energy, physiological parameters, sodium

\section{Introdução}

A tecnificação da suinocultura tem proporcionando aumento na sua produtividade e para que os animais apresentem bom desempenho é fundamental a manutenção de suas funções metabólicas, sendo que o $\mathrm{pH}$ do sangue e dos fluídos orgânicos, devem ser mantidos dentro de parâmetros adequados. Os alimentos consumidos pelos suínos interferem no $\mathrm{pH}$ e podem causar oscilação entre a alcalinidade e a acidez do organismo.

A composição mineral da ração influencia o equilíbrio ácido-básico e de acordo com Hooge (1998) as rações não possuem carga neutra, porém, todas as cargas negativas devem ser balanceadas com as positivas e a soma total dos eletrólitos influencia a regulação do equilíbrio eletrolítico do organismo animal, sendo que o sódio e o potássio possuem efeito alcalinizante, o bicarbonato tem efeito tamponante e o cloro, efeito acidificante. Existem poucas informações relacionadas às exigências de microminerais, principalmente, referentes às de eletrólitos como o sódio em dietas para suínos submetidos a temperaturas ambientais elevadas (KIEFER et al., 2010).
O equilíbrio ácido-básico do organismo do suíno está diretamente ligado aos eletrólitos ingeridos e o balanço eletrolítico da dieta (BED) pode influenciar o crescimento, o apetite, o desenvolvimento ósseo, a resposta ao estresse térmico e o metabolismo de certos nutrientes, como aminoácidos, minerais e vitaminas (PATIENCE, 1990).

A alteração do BED pode influenciar o metabolismo da proteína e de aminoácidos, ocasionando acidose subclínica com conseqüente aumento da mortalidade. Sendo o farelo de soja rico em potássio, eletrólito de grande importância no $\mathrm{BED}$, ao reduzir-se a sua quantidade na ração devese atentar para que o balanço eletrolítico não chegue a valores abaixo de $180 \mathrm{mEq} / \mathrm{kg}$ (MARTINEZAMESCUA et al., 1998).

Ao se reduzir a proteína bruta das rações, com a respectiva suplementação de aminoácidos sintéticos, é de fundamental importância o uso de substâncias para manter o adequado BED e dentre estas se encontra o bicarbonato de sódio.

Os aminoácidos básicos livres podem ser transportados de forma ativa acoplados ao $\mathrm{Na}^{+}$ou na forma passiva por difusão simples ou facilitada. Os 
peptídeos, aminoácidos e os peptídeos de glicina, serina e carnosina são absorvidos principalmente intactos e acoplados ao íon $\mathrm{H}^{+}$por ausência de peptidases específicas. Os peptídeos ácidos também são absorvidos, principalmente intactos, acoplados ao $\mathrm{H}^{+}$e são, então, hidrolisados pelas peptidases ácidas citosólicas a ácidos glutâmico e aspártico, que são transportados através da membrana basolateral por difusão simples ou, principalmente, por um sistema de transporte ativo acoplado ao $\mathrm{Na}^{+}$(FRENHANI; BURINI, 1999). Alguns transportadores de aminoácidos mostram mais dependência de certos íons $\left(\mathrm{Na}^{+}, \mathrm{Cl}^{-}\right.$e $\left.\mathrm{K}^{+}\right)$ou usam um $\mathrm{H}^{+}$no processo de transporte (GONSKA; HIRSCH; SCHLATTER, 2000).

Utilizando o bicarbonato de sódio, para aumentar o BED, Dersjant-Li et al. (2001) observaram maior digestibilidade da matéria seca e do nitrogênio em rações com $500 \mathrm{mEq} / \mathrm{kg}$, em relação àquelas contendo 100 e $200 \mathrm{mEq} / \mathrm{kg}$.

Objetivou-se com esse trabalho avaliar os níveis séricos de sódio, potássio, cloretos e uréia, assim como o balanço de nitrogênio e metabolizabilidade da energia bruta em suínos recebendo rações com redução da proteína bruta e diferentes balanços eletrolíticos da dieta por meio da utilização de bicarbonato de sódio.

\section{Material e Métodos}

O experimento foi realizado na sala de metabolismo de suínos da Universidade Estadual do Oeste do Paraná - UNIOESTE, Campus de Marechal Cândido Rondon.

Foram utilizados 16 suínos, machos castrados, com peso médio inicial de $27,95 \pm 1,27 \mathrm{~kg}$, distribuídos individualmente em gaiolas de metabolismo semelhantes às descritas por Pekas (1968). As condições ambientais foram monitoradas duas vezes ao dia em horários predeterminados (6:30h e 18:30h), com auxílio de termômetro digital de temperaturas máxima e mínima.
O delineamento experimental utilizado foi o de blocos ao acaso com quatro tratamentos e quatro repetições, sendo cada unidade experimental representada por um animal, em que os tratamentos consistiram de rações com BED de 160, 208, 257 e $305 \mathrm{mEq} / \mathrm{kg}$.

As composições aminoacídicas totais do milho e do farelo de soja, utilizados nas rações experimentais, foram analisadas na Evonik Industries. De posse dos valores de aminoácidos totais foram aplicados os coeficientes de digestibilidade ileal verdadeira propostos por Rostagno et al. (2005) a fim de estimar os seus valores de aminoácidos digestíveis verdadeiros.

Foram realizadas as análises de proteína bruta (PB) do milho e do farelo de soja, conforme a metodologia descrita por Silva e Queiroz (2005), e após a mistura das rações foram coletadas amostras e realizadas as análises de sódio e potássio.

As rações experimentais (Tabela 1) foram formuladas para atender as recomendações nutricionais propostas por Rostagno et al. (2005) com exceção da PB, que foi reduzida em 1,5\% em relação à exigência (18,13\%), suplementando-se com aminoácidos sintéticos.

Para elevar os BED das rações experimentais foram utilizados níveis crescentes de bicarbonato de sódio e decrescentes de sal comum. Os balanços eletrolíticos das rações experimentais foram calculados considerando o peso molecular de cada elemento químico, conforme recomendado por Patience (1990) por meio da equação $\mathrm{BE}=(\mathrm{Na} / 23,0$ $+\mathrm{K} / 39,0-\mathrm{Cl} / 35,5) \times 1000$.

O experimento teve duração de 12 dias, sendo sete dias de adaptação dos animais às gaiolas de metabolismo e às rações experimentais e cinco dias de coletas de fezes e urina.

A quantidade de ração fornecida diariamente aos animais foi baseada no peso metabólico $\left(\mathrm{Kg}{ }^{0,75}\right)$. Para evitar perdas e facilitar a ingestão, as rações foram umedecidas e fornecidas duas vezes ao dia (6:00h e 18:00h). 
Foi utilizado o método de coleta total de fezes, sacos plásticos e conservadas em congelador a utilizando o óxido férrico $\left(\mathrm{Fe}_{2} \mathrm{O}_{3}\right)$ como marcador, $-5^{\circ} \mathrm{C}$. No final do experimento as fezes foram sendo o início e final da coleta determinados pelo homogeneizadas, secas em estufa de ventilação aparecimento de fezes marcadas. As fezes foram forçada $\left(60^{\circ} \mathrm{C}\right.$ por $\left.72 \mathrm{~h}\right)$ e moídas para análises colhidas duas vezes ao dia, acondicionadas em posteriores.

Tabela 1. Composição das rações experimentais.

\begin{tabular}{|c|c|c|c|c|}
\hline \multirow{2}{*}{ Ingredientes } & \multicolumn{4}{|c|}{ Balanço Eletrolítico $(\mathrm{mEq} / \mathrm{kg})$} \\
\hline & 160 & 208 & 257 & 305 \\
\hline Milho grão & 70,61 & 70,61 & 70,61 & 70,61 \\
\hline Farelo de soja & 23,05 & 23,05 & 23,05 & 23,05 \\
\hline Fosfato bicálcico & 2,14 & 2,14 & 2,14 & 2,14 \\
\hline Calcário calcítico & 0,31 & 0,31 & 0,31 & 0,31 \\
\hline Óleo de soja & 1,50 & 1,50 & 1,50 & 1,50 \\
\hline Minerais ${ }^{1}$ & 0,05 & 0,05 & 0,05 & 0,05 \\
\hline Vitaminas $^{2}$ & 0,10 & 0,10 & 0,10 & 0,10 \\
\hline L-Lisina HCL & 0,27 & 0,27 & 0,27 & 0,27 \\
\hline DL-Metionina & 0,06 & 0,06 & 0,06 & 0,06 \\
\hline L-Treonina & 0,09 & 0,09 & 0,09 & 0,09 \\
\hline L-Triptofano & 0,01 & 0,01 & 0,01 & 0,01 \\
\hline Promotor de crescimento ${ }^{3}$ & 0,02 & 0,02 & 0,02 & 0,02 \\
\hline Antioxidante $^{4}$ & 0,10 & 0,10 & 0,10 & 0,10 \\
\hline Adsorvente de micotoxinas ${ }^{5}$ & 0,10 & 0,10 & 0,10 & 0,10 \\
\hline Sal comum & 0,34 & 0,27 & 0,21 & 0,15 \\
\hline Inerte $^{6}$ & 1,09 & 0,73 & 0,36 & 0,00 \\
\hline Bicarbonato de sódio & 0,16 & 0,59 & 1,02 & 1,45 \\
\hline \multicolumn{5}{|l|}{ Composição nutricional calculada } \\
\hline Energia metabolizável (kcal/Kg) & 3230 & 3230 & 3230 & 3230 \\
\hline Proteína bruta $(\%)$ & 16,63 & 16,63 & 16,63 & 16,63 \\
\hline Cálcio (\%) & 0,720 & 0,720 & 0,720 & 0,720 \\
\hline Fósforo disponível (\%) & 0,400 & 0,400 & 0,400 & 0,400 \\
\hline Sódio (\%) & 0,200 & 0,289 & 0,382 & 0,471 \\
\hline Cloro (\%) & 0,304 & 0,267 & 0,227 & 0,190 \\
\hline Potássio (\%) & 0,621 & 0,621 & 0,621 & 0,621 \\
\hline Lisina dig. Suínos (\%) & 0,991 & 0,991 & 0,991 & 0,991 \\
\hline Met.+Cist. dig. Suíno (\%) & 0,555 & 0,555 & 0,555 & 0,555 \\
\hline Treonina dig. Suínos (\%) & 0,624 & 0,624 & 0,624 & 0,624 \\
\hline Triptofano dig. Suínos (\%) & 0,168 & 0,168 & 0,168 & 0,168 \\
\hline
\end{tabular}

${ }^{1}$ Conteúdo/kg: ferro, 100g; cobre, $10 \mathrm{~g}$; cobalto, $1 \mathrm{~g}$; manganês, $40 \mathrm{~g}$; zinco, $100 \mathrm{~g}$; iodo, 1,5g; e veículo q.s.p. p/ 1000g; ${ }^{2}$ Conteúdo/ kg: vit. A, 10.000.000 U.I.; vit. $\mathrm{D}_{3}$, 1.500 .000 U.I.; vit. E, 30.000 U.I.; vit. $\mathrm{B}_{1}, 2,0 \mathrm{~g}$; vit. $\mathrm{B}_{2}, 5,0 \mathrm{~g}$; vit. $\mathrm{B}_{6}$, 3,0g; vit. $\mathrm{B}_{12}$, 30.000mcg; ácido nicotínico, $30.000 \mathrm{mcg}$; ácido pantotênico, $12.000 \mathrm{mcg}$; vit. $\mathrm{K}_{3}, 2.000 \mathrm{mg}$; ácido fólico, $800 \mathrm{mg}$; biotina, 100mg; selênio, 300mg; e veículo q.s.p., 1.000g; ${ }^{3}$ Fosfato de tilosina; ${ }^{4}$ Butil Hidróxi Tolueno; ${ }^{5}$ Toxisorb. ${ }^{6}$ Areia fina lavada.

Fonte: Elaboração dos autores. 
A urina foi drenada em baldes plásticos contendo $20 \mathrm{~mL}$ de ácido clorídrico $(\mathrm{HCl})$ 1:1, e colhida uma vez ao dia, pela manhã (7:00h). Ao término da coleta de urina foi realizada a limpeza das gaiolas, coletores e baldes plásticos utilizando água deionizada, sendo que não foi adicionado o ácido clorídrico nos baldes com o intuído de não interferir nos valores de $\mathrm{pH}$ da urina. Na medida em que os animais excretavam, a urina era imediatamente submetida à leitura do $\mathrm{pH}$ por meio de um medidor de $\mathrm{pH}$ portátil.

As análises das fezes e urina foram realizadas segundo a metodologia descrita por Silva e Queiroz (2005) sendo realizadas as análises de matéria seca (MS), nitrogênio (N) e energia bruta (EB) das fezes, e $\mathrm{N}$ e EB da urina.

Após o período das coletas de fezes e urina foi realizada a coleta de sangue, através de punção na veia cava, seguindo os procedimentos descritos por Dersjant-Li et al. (2001), em que o sangue foi coletado duas horas após o arraçoamento da manhã (08:30h). Foram coletados $10 \mathrm{ml}$ de sangue de cada animal, em tubos do tipo Vacutainer sem anticoagulante, sendo posteriormente centrifugados a $3000 \mathrm{rpm}$ por dez minutos, para obtenção do soro.

Foram realizadas as análises de cloretos e uréia do soro utilizando kits comerciais específicos, seguindo os procedimentos operacionais padrão específicos e posteriormente realizadas as leituras de absorbância utilizando um espectrofotômetro UV-Vis. As análises de sódio e potássio foram realizadas utilizando um fotômetro de chama, sendo as amostras de soro previamente diluídas em água destilada e deionizada.

Em relação ao balanço de nitrogênio foram determinados o nitrogênio ingerido ( $\mathrm{N}$ ingerido), nitrogênio excretado nas fezes ( $\mathrm{N}$ fezes), nitrogênio excretado na urina ( $\mathrm{N}$ urina), $\mathrm{N}$ absorvido, $\mathrm{N}$ retido, $\mathrm{N}$ absorvido/ $\mathrm{N}$ retido e excreção total de $\mathrm{N}$.
Foram também determinados os valores de energia digestível (ED) e metabolizável (EM), os coeficientes de digestibilidade (CDEB) e metabolizabilidade (CMEB) da energia bruta e a relação EM:ED.

Os dados foram submetidos à análise de variância e de regressão em função dos níveis de balanço eletrolítico das rações experimentais, adotandose os modelos de regressão linear ou quadrático, de acordo com o melhor ajuste obtido para cada variável. As análises estatísticas foram realizadas por meio do Sistema de Análises Estatísticas e Genéticas - SAEG, desenvolvido pela Universidade Federal de Viçosa (UFV, 1999).

\section{Resultados e Discussão}

$\mathrm{O} \mathrm{pH}$ da urina aumentou linearmente $(\mathrm{P}<0,05)$ com os diferentes balanços eletrolíticos estudados (Figura 1) variando de 6,90 a 8,03 (Tabela 2). Da mesma forma, Budde e Crenshaw (2003) trabalhando com BED de -35, 112 e $212 \mathrm{mEq} /$ $\mathrm{kg}$ constataram aumento no $\mathrm{pH}$ da urina, obtendo valores de 5,71; 6,02 e 7,65 de pH, respectivamente. $\mathrm{O}$ pH urinário obtido para o valor de $210 \mathrm{mEq} / \mathrm{kg}$ $\operatorname{BED}(7,91)$ assemelha-se ao valor de 7,65 obtido pelos autores supracitados, quando utilizaram BED de $212 \mathrm{mEq} / \mathrm{kg}$.

$\mathrm{O}$ aumento no $\mathrm{pH}$ urinário pode ser devido a sua importância na excreção do excesso de $\mathrm{H}^{+}$do organismo, estabilizando o estado fisiológico do animal (DEROUCHEY et al., 2003) podendo estar relacionado com a excreção do excesso do íon $\mathrm{H}^{+}$ corporal pelos rins, sendo controlada por meio do aumento na excreção de íons fosfato monobásicos e amônia pelos rins, enquanto íons bicarbonato são reabsorvidos para atender as necessidades endógenas (GOLZ; CRENSHAW, 1991). 
Figura 1. Balanços eletrolíticos $(\mathrm{BE})$ da dieta sobre o pH urinário, sódio e uréia séricos de suínos.

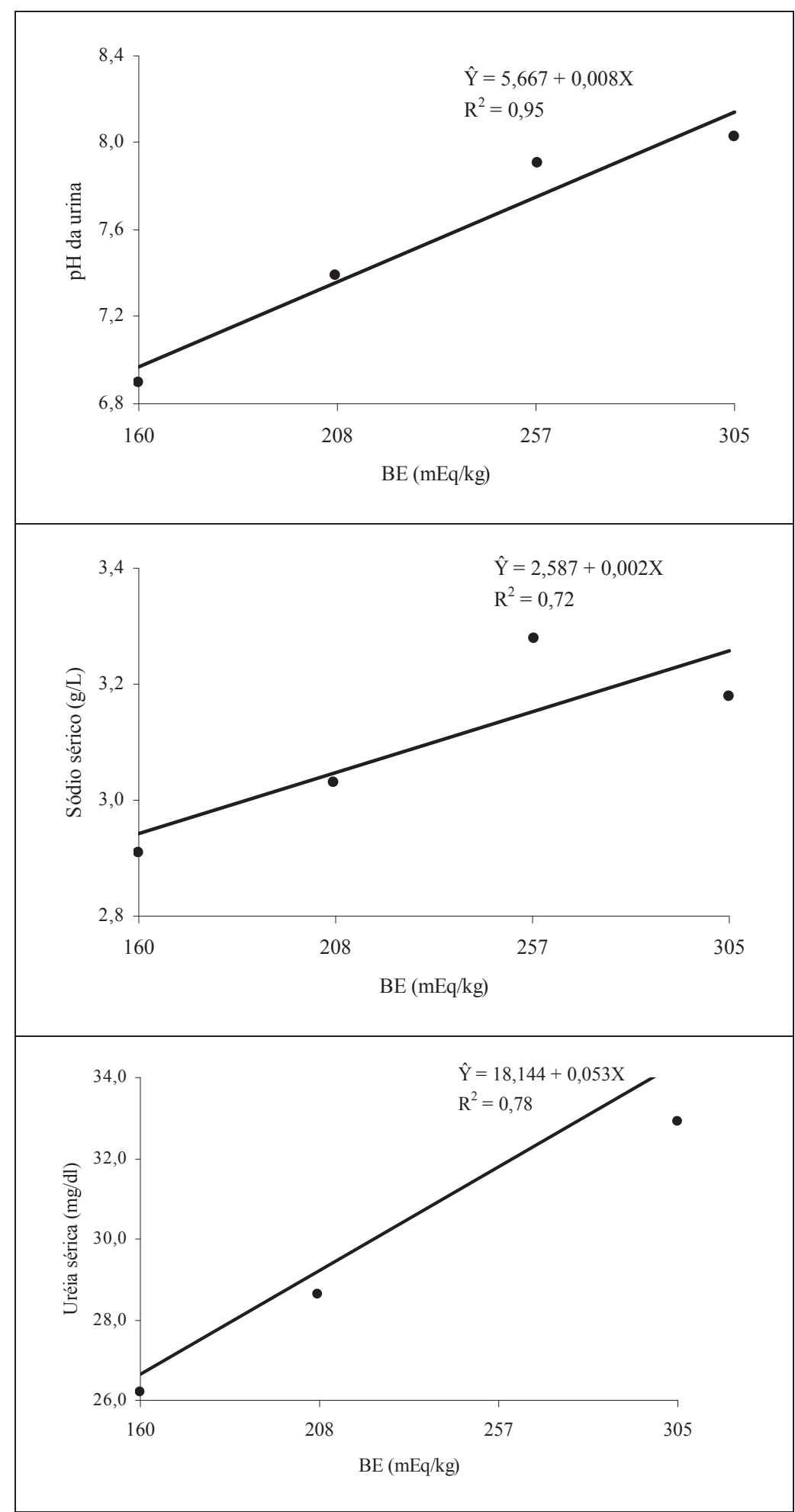

Fonte: Elaboração dos autores. 
Tabela 2. Influência do balanço eletrolítico das rações sobre os parâmetros sanguíneos e pH da urina de suínos.

\begin{tabular}{|c|c|c|c|c|c|}
\hline & \multicolumn{4}{|c|}{ Balanço eletrolítico $(\mathrm{mEq} / \mathrm{kg})$} & \multirow{2}{*}{$\mathrm{CV}(\%)$} \\
\hline & 160 & 208 & 257 & 305 & \\
\hline $\mathrm{pH}_{\text {urina }}{ }^{1}$ & 6,90 & 7,39 & 7,91 & 8,03 & 6,67 \\
\hline Cloretos $(\mathrm{mEq} / \mathrm{L})$ & 115,30 & 110,84 & 105,85 & 108,74 & 7,65 \\
\hline Potássio (mg/L) & 216,28 & 226,50 & 221,50 & 217,00 & 7,14 \\
\hline Sódio $(g / L)^{1}$ & 2,91 & 3,03 & 3,28 & 3,18 & 3,31 \\
\hline Uréia $(\mathrm{mg} / \mathrm{dl})^{1}$ & 26,21 & 28,64 & 34,32 & 32,89 & 5,90 \\
\hline
\end{tabular}

Fonte: Elaboração dos autores.

Por outro lado, Golz e Crenshaw (1991) observaram redução do $\mathrm{pH}$ urinário dos suínos ao elevarem os níveis de cloro nas rações, sendo esta redução ainda maior ao aumentarem os níveis de potássio. Estes resultados são contrários aos obtidos no presente trabalho, em que os níveis de sódio foram aumentados pelo uso do bicarbonato de sódio e os níveis de cloro foram reduzidos ao se retirar gradativamente o sal das rações, proporcionando então níveis de cloro com perfil oposto em relação aos utilizados pelos autores supracitados. Budde e Crenshaw (2003) relataram que devido à regulação fisiológica do balanço osmótico, o excesso de cloro da dieta pode tanto ser excretado como uma forma de balancear os cátions ou serem armazenados no organismo como forma de reposição de outro ânion. No entanto, a redução dos níveis de cloro nas rações avaliadas não proporcionou alterações na concentração de cloro sérico (Tabela 2).

Não foram observadas diferenças estatísticas significativas $(\mathrm{P}>0,05)$ na concentração de cloretos no soro sanguíneo (Tabela 2) em função do aumento no BE. Estes resultados estão de acordo com os obtidos por Savaris (2008) que não observou alterações nas concentrações de cloretos no soro de suínos ao avaliar rações com 16,80 (159 e $251 \mathrm{mEq} /$ $\mathrm{kg}$ ) e 13,80\% (135 e $260 \mathrm{mEq} / \mathrm{kg}$ ) de proteína bruta.

As concentrações de cloretos no soro sanguíneo (Tabela 2) diferem dos valores apresentados por Dersjant-li et al. (2001), que observaram menor concentração plasmática de cloretos nos suínos que receberam ração com $\mathrm{BE}$ de $-100 \mathrm{mEq} / \mathrm{kg}$, em relação aos tratamentos com 200 e 500 mEq/ $\mathrm{kg}$. No entanto, os autores utilizaram cloreto de cálcio para obtenção do $\mathrm{BE}$ de $-100 \mathrm{mEq} / \mathrm{kg}$, o que proporcionou o maior nível de cloro em relação aos demais BE avaliados.

De acordo com Budde e Crenshaw (2003) o aumento do $\mathrm{BE}$ causa redução dos níveis plasmáticos e séricos de cloro, e Dersjant-li et al. (2001) e Budde e Crenshaw (2003) relataram que a concentração deste íon apresenta relação direta com seus teores na ração, no entanto, no presente trabalho as concentrações de cloro na ração reduziram com o respectivo aumento do $\mathrm{BE}$ e não foram observadas diferenças nas concentrações de cloretos no soro.

Não foram observadas alterações significativas $(\mathrm{P}>0,05)$ nas concentrações séricas de potássio (Tabela 2), corroborando os resultados observados na literatura científica consultada (HAYDON; WEST, 1990; PATIENCE; WOLYNETZ, 1990; DERSJANT-LI et al., 2002).

De acordo com Dersjant-li et al. (2001) a constância nas concentrações de potássio no plasma é devido ao seu nível constante nas rações. No presente trabalho se observa variação mínima dos níveis de potássio nas rações experimentais, pois para obter os BE avaliados foram alterados os níveis de sódio e cloro, sem alterações nos níveis de potássio.

Os valores obtidos para o sódio no soro 
sanguíneo são substancialmente maiores em relação a cloretos e potássio (Tabela 2), o que se explica em virtude de sódio constituir grande parte das bases do soro sanguíneo, principalmente nos líquidos extracelulares.

A concentração de sódio no soro sanguíneo apresentou diferença significativa $(\mathrm{P}<0,01)$ entre os tratamentos, observando-se aumento na sua concentração em função do aumento do BE, (Figura 1). Da mesma forma Dersjant-li et al. (2002) observaram aumento na concentração de sódio no sangue de suínos ao avaliarem os BE de $-100 \mathrm{mEq} /$ $\mathrm{kg}$ e $200 \mathrm{mEq} / \mathrm{kg}$. Haydon e West (1990) também observaram aumento linear na concentração de sódio no sangue com o aumento do BE.

O aumento de sódio no soro sanguíneo pode ser explicado pelo aumento da sua concentração na ração (Tabela 1) proporcionado pelo uso de bicarbonato de sódio para elevar o BE. Além disso, Van Der Klis, Verstegen e Van Voorst (1993) relataram que a redução na concentração de sódio no sangue, em função do menor $\mathrm{BE}$, pode estar relacionado à secreção extra de bicarbonato de sódio do pâncreas para o intestino delgado, para manter ou alcançar um $\mathrm{pH}$ intestinal adequado.
A concentração de uréia no soro sanguíneo aumentou linearmente $(\mathrm{P}<0,01)$ com o respectivo aumento do BE da ração (Figura 1), o que pode estar relacionado à maior absorção de aminoácidos cujos transportadores são sódio-dependentes, uma vez que para elevar os BED foi adicionado o bicarbonato de sódio proporcionando aumento dos níveis de sódio nas rações experimentais. Por outro lado, Savaris (2008) avaliando diferentes BE em rações para suínos não observou diferença na concentração de uréia no soro sanguíneo.

Não foram observadas diferenças significativas $(\mathrm{P}>0,05)$ do BED sobre as variáveis relacionadas ao balanço de nitrogênio (Tabela 3). $\mathrm{O}$ aumento da uréia no soro sanguíneo $(\mathrm{P}<0,05)$ poderia repercutir no aumento do $\mathrm{N}$ absorvido. Da mesma forma, o aumento dos níveis de sódio nas rações experimentais poderia proporcionar maior absorção de nitrogênio, uma vez que os aminoácidos livres presentes no intestino delgado são co-transportados juntamente com o sódio e seu transporte depende do gradiente eletroquímico de sódio, gerado pelo transporte ativo primário $\mathrm{Na}^{+}-\mathrm{K}^{+}$-ATPase na membrana basolateral, sendo chamado de transporte ativo secundário. Além disso, os carreadores de aminoácido apresentam sítios de ligação para moléculas de aminoácidos e para o sódio (FRENHANI; BURINI, 1999).

Tabela 3. Influência do balanço eletrolítico das rações sobre o metabolismo do nitrogênio em suínos.

\begin{tabular}{lrrrrr}
\hline & \multicolumn{3}{c}{ Balanço eletrolítico (mEq/kg) } & \multicolumn{2}{c}{ CV } \\
\cline { 2 - 5 } & 160 & 208 & 257 & 305 & $(\%)$ \\
\hline N ingerido (g/dia) & 29,42 & 28,74 & 29,02 & 28,61 & 2,58 \\
N excretado nas fezes (g/dia) & 4,99 & 5,89 & 5,61 & 4,58 & 11,90 \\
N excretado na urina (g/dia) & 10,03 & 8,22 & 9,17 & 9,19 & 15,25 \\
N absorvido (g/dia) & 24,43 & 22,85 & 23,41 & 24,04 & 3,45 \\
N retido (g/dia) & 14,40 & 14,63 & 14,24 & 14,84 & 9,41 \\
N retido/N absorvido (\%) & 58,37 & 64,82 & 60,48 & 61,41 & 10,58 \\
Excreção total N (g/dia) & 15,03 & 14,11 & 14,78 & 13,77 & 11,12 \\
\hline
\end{tabular}

Fonte: Elaboração dos autores. 
Entretanto, esse efeito não foi verificado, possivelmente, devido à estreita faixa de BED avaliados (160 a $305 \mathrm{mEq} / \mathrm{kg})$. Por outro lado, avaliando o BE em rações para suínos de -100, 200 e $500 \mathrm{mEq} / \mathrm{kg}$, Dersjant-li et al. (2001) observaram diferenças na digestibilidade do nitrogênio, obtendo maior valor para o BED de $500 \mathrm{mEq} / \mathrm{kg}$. Da mesma forma, Haydon e West (1990) verificaram aumento na digestibilidade do $\mathrm{N}$ e dos aminoácidos no final do intestino delgado de suínos, com exceção da metionina, em função do aumento do BE das rações $(-50,100,250$ e $400 \mathrm{mEq} / \mathrm{kg})$, influenciando a relação $\mathrm{N}$ retido/ $\mathrm{N}$ absorvido, que apresentou maiores valores em função do aumento do BE das rações. Estes resultados não foram observados no presente trabalho $(\mathrm{P}>0,05)$, sendo observadas apenas alterações numéricas para estas variáveis.

No entanto, a concentração de uréia no soro sanguíneo aumentou em função dos maiores BE das rações (Figura 1), sugerindo mais estudos sobre a digestibilidade ileal de aminoácidos em função do $\mathrm{BE}$ da ração. Além disso, os coeficientes de variação obtidos para $\mathrm{N}$ excretado nas fezes e $\mathrm{N}$ excretado na urina podem ser considerados elevados, o que pode ter causado a obtenção de resultados semelhantes $(\mathrm{P}>0,05)$, principalmente para o $\mathrm{N}$ excretado na urina.
A variação no $\mathrm{BE}$ das rações, de 160 para 305 $\mathrm{mEq} / \mathrm{kg}$, não influenciou $(\mathrm{P}>0,05)$ os coeficientes de digestibilidade da energia bruta (Tabela 4). Haydon e West (1990) por sua vez, observaram que a energia digestível das rações reduziu linearmente em função do aumento do BE das rações, o que segundo os autores, pode ser explicado pelo decréscimo no valor de energia bruta das rações, devido a utilização do NaHCO3 para elevar o BE das rações. No presente trabalho não foram verificadas alterações $(\mathrm{P}>0,05)$ nos valores de energia digestível (Tabela 4) entre os tratamentos, no entanto, o bicarbonato de sódio foi incluído nas rações às custas do inerte e do sal, ingredientes sem valor calórico, cuja inclusão não chegou a influenciar a energia bruta das rações.

Os coeficientes de metabolizabilidade da energia bruta também não foram influenciados $(\mathrm{P}>0,05)$ pelos balanços eletrolíticos avaliados (Tabela 4), e variaram de 84,25 a $83,47 \%$, referentes aos tratamentos com balanços eletrolíticos de 160 e 305 $\mathrm{mEq} / \mathrm{kg}$, respectivamente. Da mesma forma Haydon e West (1990) ao avaliarem rações com balanço eletrolítico de -50 a $400 \mathrm{mEq} / \mathrm{kg}$, formuladas para conter de 3,82 a 3,79 Mcal/kg de energia bruta, não observaram diferenças na digestibilidade total da energia bruta, mas verificaram aumento linear na digestibilidade no final do intestino delgado.

Tabela 4. Balanço eletrolítico em rações para suínos sobre os coeficientes de digestibilidade e metabolizabilidade da energia bruta, valores de energia digestível e metabolizável.

\begin{tabular}{|c|c|c|c|c|c|}
\hline & \multicolumn{4}{|c|}{ Balanço eletrolítico $(\mathrm{mEq} / \mathrm{kg})$} & \multirow[b]{2}{*}{$\mathrm{CV}(\%)$} \\
\hline & 160 & 208 & 257 & 305 & \\
\hline $\mathrm{EB}(\mathrm{kcal} / \mathrm{kg})$ & 3842 & 3842 & 3842 & 3842 & - \\
\hline CDEB (\%) & 87,76 & 87,03 & 86,99 & 86,92 & 1,39 \\
\hline $\mathrm{ED}(\mathrm{kcal} / \mathrm{kg})$ & 3372 & 3344 & 3342 & 3339 & 1,42 \\
\hline CMEB (\%) & 84,25 & 83,55 & 83,62 & 83,47 & 1,29 \\
\hline $\mathrm{EM}(\mathrm{kcal} / \mathrm{kg})$ & 3237 & 3210 & 3212 & 3207 & 1,32 \\
\hline EM:ED & 0,96 & 0,96 & 0,96 & 0,96 & 0,33 \\
\hline
\end{tabular}

CDEB: coeficiente de digestibilidade da energia bruta

ED: energia digestível

CMEB: coeficiente de metabolizabilidade da energia bruta

EM: energia metabolizável

NS: não significativo

Fonte: Elaboração dos autores. 


\section{Conclusão}

O aumento do balanço eletrolítico da dieta, de 160 a $305 \mathrm{mEq} / \mathrm{kg}$, proporcionou maiores concentrações de uréia e sódio do soro sanguíneo, e maiores valores de $\mathrm{pH}$ na urina de suínos na fase inicial.

\section{Referências}

BUDDE, R. A.; CRENSCHAW, T. D. Chronic metabolic acid load induced by changes in dietary electrolyte balance increased chloride retention but did not compromise bone in growing swine. Journal of Animal Science, Savoy, v. 81, n. 1, p. 197-208, 2003.

DERSJANT-LI, Y.; VERSTEGEN, M. W. A.; JANSMAN, A.; SCHULZE, H.; SCHRAMA, J. W.; VERRETH, J. A. Changes in oxygen content and acidbase balance in arterial and portal blood in response to the dietary electrolyte balance in pigs during a 9-h period after a meal. Journal of Animal Science, Savoy, v. 80, n. 5, p. 1233-1239, 2002.

DEROUCHEY, J. M.; HANCOCK, J. D.; HINES, R. H.; CUMMINGS, K. R.; LEE, D. J.; MALONEY, C. A.; DEAN, D. W.; PARK, J. S.; CAO, H. Effects of dietary electrolyte balance on the chemistry of blood and urine in lactating sows and sow litter performance. Journal of Animal Science, Savoy, v. 81, n. 12, p. 3067-3074, 2003.

DERSJANT-LI, Y.; SCHULZE, H.; SCHRAMA, J. W.; VERRETH, J. A.; VERSTEGEN, M. W. A. Feed intake, growth, digestibility of dry matter and nitrogen in young pigs as affected by dietary cation-anion difference and supplementation of xylanase. Journal Animal Physiology Animal Nutrition, Berlin, v. 85, n. 3-4, p. 101-109, 2001.

FRENHANI, P. B.; BURINI, R. C. Mecanismos de absorção de aminoácidos e oligopeptídios. Controle e implicações na dietoterapia humana. Arquivo Gastroentrol., Botucatu, v. 36, n. 4, p. 227-237, 1999.

GOLZ, D. I.; CRENSHAW, T. D. The effect of dietary potassium and chloride on cation-anion balance in swine. Journal of Animal Science, Savoy, v. 69, n. 6, p. 25042515, 1991.

GONSKA, T.; HIRSCH, J. R.; SCHLATTER, E. Amino acid transport in the renal proximal tubule. Amino Acids, Münster, v. 19, n. 2, p. 395-407, 2000.

HAYDON, K. D.; WEST, J. W. Effect of dietary electrolyte balance on nutrient digestibility determined at end of the small intestine and over the total digestive tract in growing pigs. Journal of Animal Science, Savoy, v. 68, n. 11, p. 3687-3693, 1990.

HOOGE, D. M. Electrolyte balance in turkeys, layers examined. Feedstuffs, USA, v. 70, n. 18, p. 17-19, 1998.

KIEFER, C.; MORAIS, M. G.; SANCHES, J. F.; YOSHIDA, F. Y.; SANTOS, A. P.; LUZ, M. F.; NANTES, C. L. Sódio para leitões dos 9 aos $25 \mathrm{~kg}$ mantidos sob conforto térmico. Revista Brasileira de Saúde e Produção Animal, Salvador, v. 11, n. 2, p. 386-394, 2010.

MARTINEZ-AMEZCUA, C.; LAPARRA-VEGA, J. L.; AVILA-GONZALEZ, E.; CORTES-POBLANO, U.; KIDD, M. T. Dietary lysine and electrolyte balance do not interact to affect broiler performance. Journal of Applied Poultry Research, Champaign, v. 7, n. 3, p. 313319, 1998.

PATIENCE, J. F. A review of the role acid-base balance in amino acid nutrition. Journal of Animal Science, Savoy, v. 68, n. 2, p. 398-408, 1990.

PATIENCE, J. F.; WOLYNETZ, M. S. Influence of dietary undetermined anion on acid-base status and performance in pigs. Journal of Nutrition, Bethesda, v. 120 , n. 6, p. 579-587, 1990.

PEKAS, J. C. Versatile swine laboratory apparatus for physiology and metabolic studies. Journal of Animal Science, Savoy, v. 27, n. 5, p. 1303-1306, 1968.

ROSTAGNO, H. S.; ALBINO, L. F. T.; DONZELE, J. L.; GOMES, P. C.; OLIVEIRA, R. F.; LOPES, D. C.; FERREIRA, A. S.; BARRETO, S. L. T. Composição de alimentos e exigências nutricionais. Tabelas brasileiras para aves e suínos. 2. ed. Viçosa: UFV, 2005. 186 p.

SAVARIS, V. D. L. Estudo do balanço eletrolítico e da proteína bruta da ração para suínos em crescimento em condições de alta temperatura. 2008. Dissertação (Mestrado em Produção Animal) - Universidade Estadual do Norte Fluminense Darcy Ribeiro. Campos dos Goytacazes, Rio de Janeiro.

SILVA, D. J.; QUEIROZ, A. C. Análise de alimentos: métodos químicos e biológicos. 3. ed. Viçosa: UFV, 2005. $235 \mathrm{p}$.

UNIVERSIDADE FEDERAL DE VIÇOSA - UFV. Manual de utilização do programa SAEG. Sistema para análises estatísticas e genéticas. Viçosa: UFV, 1999. 59 p.

VAN DER KLIS, J. D.; VERSTEGEN, M. W. A.; VAN VOORST, A. Effect of a soluble polysacchride (carboxy methyl cellulose) on the absortion of minerals from the gastrointestinal tract of broilers. British Poultry Science, Edinburgh, v. 34, n. 5, p. 377-389, 1993. 